\title{
Antiviral activity of the EB peptide against zoonotic poxviruses
}

Sharon E Altmann ${ }^{1 *}$, Curtis R Brandt ${ }^{2}$, Peter B Jahrling ${ }^{1,3}$ and Joseph E Blaney ${ }^{1}$

\begin{abstract}
Background: The EB peptide is a 20-mer that was previously shown to have broad spectrum in vitro activity against several unrelated viruses, including highly pathogenic avian influenza, herpes simplex virus type I, and vaccinia, the prototypic orthopoxvirus. To expand on this work, we evaluated EB for in vitro activity against the zoonotic orthopoxviruses cowpox and monkeypox and for in vivo activity in mice against vaccinia and cowpox.

Findings: In yield reduction assays, $\mathrm{EB}$ had an $\mathrm{EC}_{50}$ of $26.7 \mu \mathrm{M}$ against cowpox and $4.4 \mu \mathrm{M}$ against monkeypox. The $\mathrm{EC}_{50}$ for plaque reduction was $26.3 \mu \mathrm{M}$ against cowpox and $48.6 \mu \mathrm{M}$ against monkeypox. A scrambled peptide had no inhibitory activity against either virus. EB inhibited cowpox in vitro by disrupting virus entry, as evidenced by a reduction of the release of virus cores into the cytoplasm. Monkeypox was also inhibited in vitro by EB, but at the attachment stage of infection. EB showed protective activity in mice infected intranasally with vaccinia when co-administered with the virus, but had no effect when administered prophylactically one day prior to infection or therapeutically one day post-infection. EB had no in vivo activity against cowpox in mice.
\end{abstract}

Conclusions: While EB did demonstrate some in vivo efficacy against vaccinia in mice, the limited conditions under which it was effective against vaccinia and lack of activity against cowpox suggest EB may be more useful for studying orthopoxvirus entry and attachment in vitro than as a therapeutic against orthopoxviruses in vivo.

Keywords: EB peptide, vaccinia, cowpox, monkeypox, poxvirus entry, poxvirus attachment

\section{Findings}

The EB peptide $\left(\mathrm{NH}_{2}\right.$ - RRKKAAVALLPAVLLALLAP$\mathrm{COOH}$ ) is a 20-mer derived from the signal peptide of the human FGF4 protein [1] and was originally identified as an inhibitor of herpes simplex virus entry [2]. Subsequent work demonstrated that EB was active against several strains of influenza virus both in vitro and in vivo [3], with a minimum of 13 core amino acids being identified as necessary to block influenza attachment to host cells [4]. EB was also identified as an inhibitor of Vaccinia virus entry into host cells in vitro [5]. This broad range of antiviral activity against a number of unrelated viruses, in combination with low in vivo toxicity [6], makes EB an attractive candidate for a broad-spectrum antiviral therapy.

Vaccinia virus (VACV) is the most-studied member of the orthopoxviruses, a genus of large, double-stranded DNA virus whose most notorious member, Variola virus,

\footnotetext{
* Correspondence: altmannse@niaid.nih.gov

'Emerging Viral Pathogens Section, National Institute of Allergy and

Infectious Diseases, National Institutes of Health, Bethesda, MD 20892, USA

Full list of author information is available at the end of the article
}

the etiologic agent of smallpox, was declared eradicated in 1980 [7]. Vaccinia virus infection typically results in a selflimiting infection in immunocompetent individuals; the closely-related cowpox (CPXV) and monkeypox (MPXV) viruses, however, are both considered to be emerging zoonotic agents $[8,9]$ with the potential to cause serious morbidity and, in the case of MPXV, mortality in infected hosts [10]. There are currently no FDA-approved therapeutics for treating orthopoxvirus infections, and vaccination is counter-indicated for an increasingly large percentage of the global population, highlighting the need for novel therapeutic options. The relatively low global incidence of severe orthopoxvirus disease, however, makes identifying broad spectrum drugs with activity against a number of unrelated viruses, including the orthopoxviruses, economically advantageous. To expand upon the initial characterization of EB peptide anti-orthopoxvirus activity, the goals of this work were to test EB for efficacy against CPXV and MPXV in vitro, to begin to determine the mechanism for any inhibition observed, and to test EB
C Biomed Central 


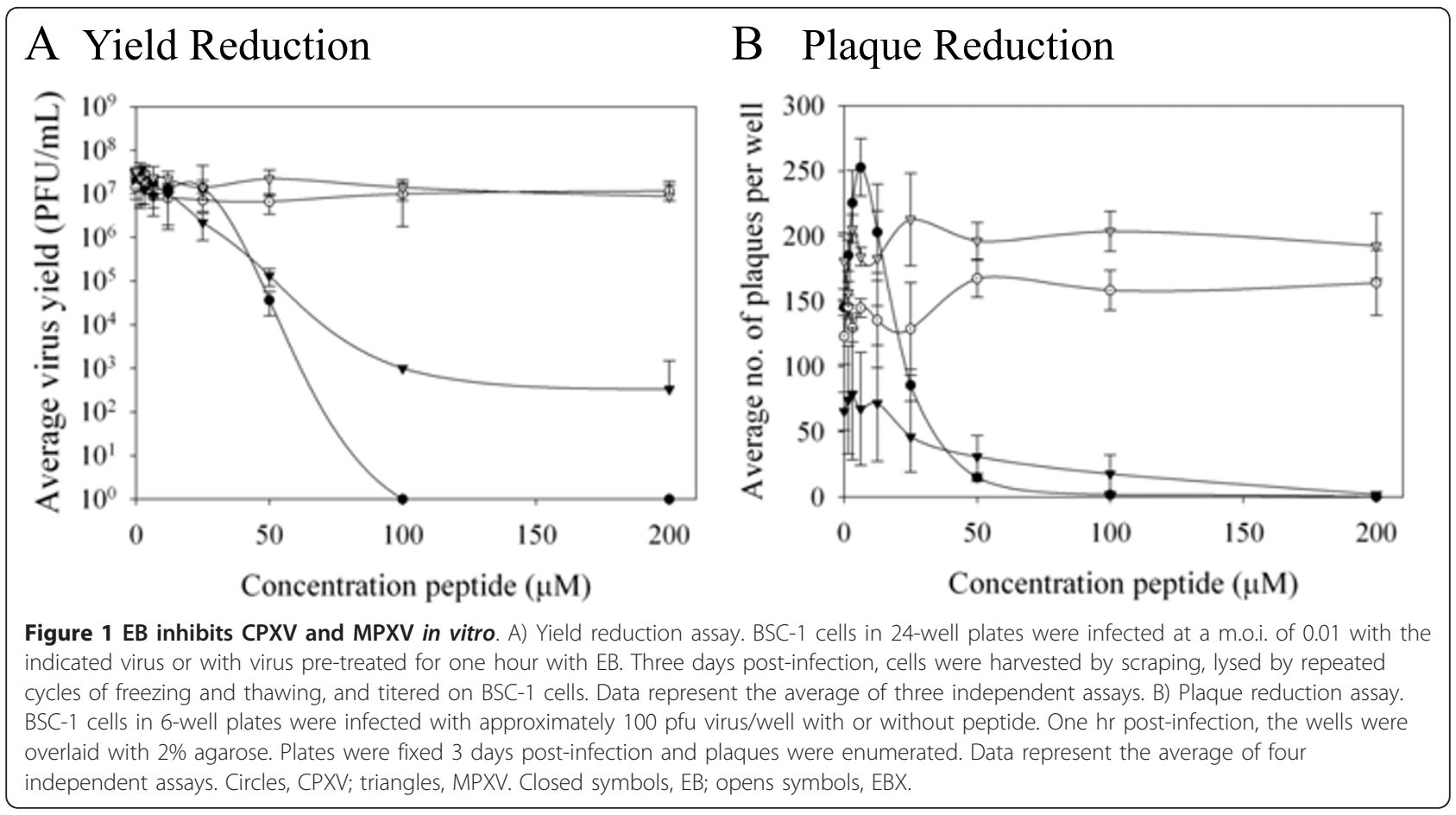

for in vivo activity in two well-characterized mouse models of orthopoxvirus disease, VACV and CPXV.

To determine whether EB had antiviral activity against CPXV (Brighton strain) and MPXV (Zaire 76 strain), the effect of increasing concentrations of the peptide (American Peptide Company, Inc., Vista, CA) on virus yield was determined (Figure 1A). All peptides used were synthesized with all dextral amino acids to reduce proteolysis. The $50 \%$ effective concentration $\left(\mathrm{EC}_{50}\right)$ of $\mathrm{EB}$ against CPXV was $26.7 \mu \mathrm{M}$, while MPXV was more sensitive to EB with an $\mathrm{EC}_{50}$ of $4.4 \mu \mathrm{M}$. The EBX peptide $\left(\mathrm{NH}_{2}-\right.$ RRKLLAALPLVLAAPLAVLA-COOH), a derivative of EB with a scrambled signal sequence failed to significantly reduce CPXV or MPXV yield, indicating that the

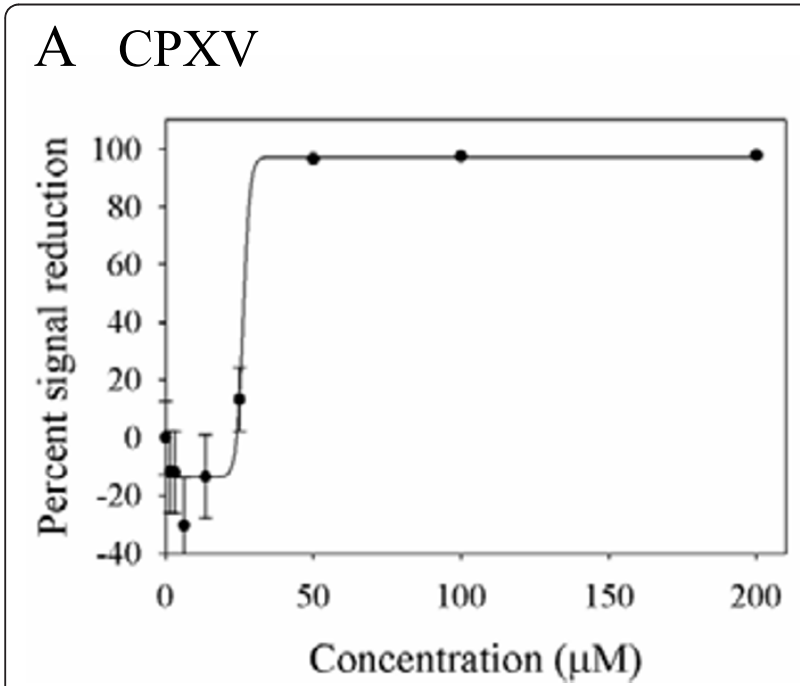

\section{B MPXV}

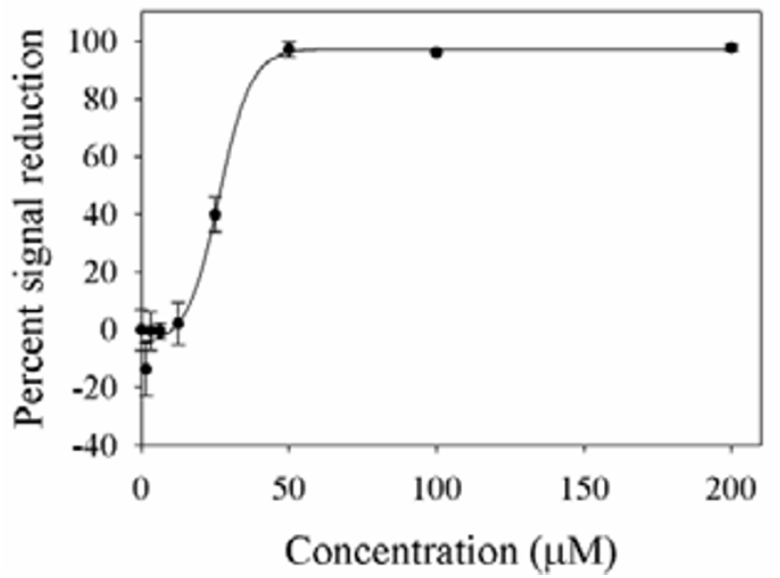

Figure 2 EB reduces gene expression in CPXV and MPXV. Triplicate wells of BSC-1 cells were infected with recombinant CPXV (A) or recombinant MPXV (B) expressing GFP under the control of an artificial early/late promoter at a m.o.i. of 1 in the presence of EB for $1 \mathrm{hr}$ at $4^{\circ} \mathrm{C}$, rinsed 3 times, and treated with peptide-containing media. Twenty-four hours post-infection, GFP intensity was measured at $520 \mathrm{~nm}$. Data are representative of three independent assays. 


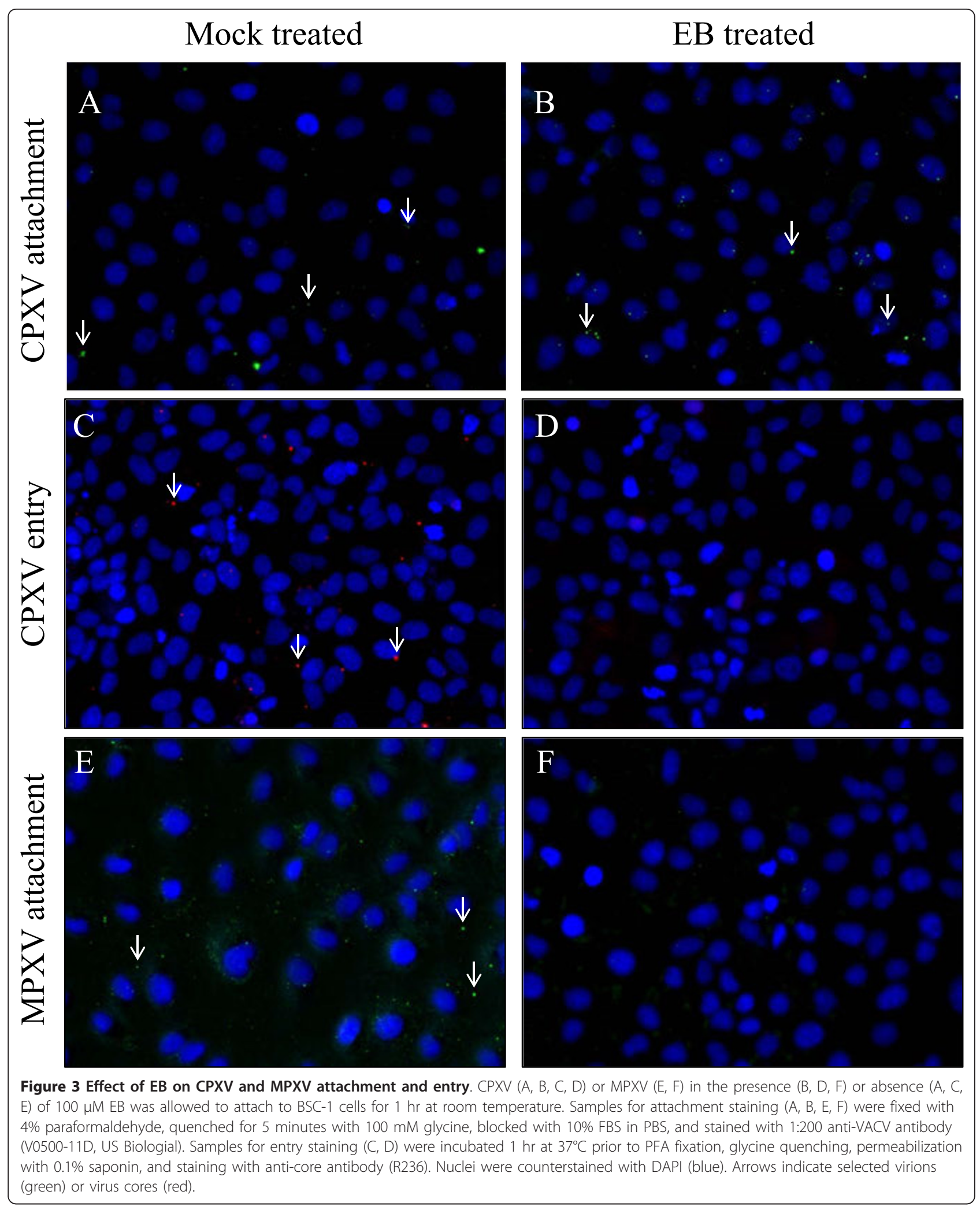


inhibition seen with the parent peptide was sequence-specific. EB was also active against CPXV and MPXV in plaque reduction assays, with $\mathrm{EC}_{50}$ values of 26.3 and 48.6 $\mu \mathrm{M}$, respectively, whereas EBX had no effect on either virus (Figure 1B). The different susceptibilities of CPXV and MPXV to EB in these two assays suggested that EB was acting differently on the two viruses. As EBX showed no activity against either virus, it was not included in further assays.

EB was next tested for its ability to reduce gene expression during CPXV and MPXV infections (Figure 2). BSC1 cells were infected with recombinant CPXV or MPXV expressing GFP under the control of a synthetic early/ late promoter in the presence of increasing concentrations of EB. The EB peptide reduced GFP expression by both viruses, with an $\mathrm{EC}_{50}$ of $26.7 \mu \mathrm{M}$ against $\mathrm{CPXV}$ and $27.6 \mu \mathrm{M}$ against MPXV, indicating that EB acted upstream of gene expression to inhibit both viruses.

Orthopoxvirus cores are only accessible to antibodies after being released into the cytoplasm, allowing for the differentiation between attached and entered virus using virion-specific or core-specific antibodies, respectively [11]. To examine whether EB was disrupting virus attachment or entry into the cells, immunofluorescent microscopy was used to quantify the number of attached and entered viruses per cell for 100 cells in the absence or presence of $100 \mu \mathrm{M}$ EB. The presence of EB had no significant effect on the number of CPXV virions attached to cells (5.4 virions/cell, untreated vs.4.7 virions/cell, treated, $p>0.01$; Figure 3Avs. 3B) but significantly reduced virus entry (1.3 cores/cell, untreated $v s .0 .3$ cores/cell, treated, $p$ $<0.0001$; Figure 3Cvs. 3D). These data are similar to what has been reported with VACV, where virus attachment was unaffected by peptide treatment but core release was significantly reduced [5]. In contrast, MXPV attachment was significantly inhibited by EB (3.2 virions/cell, untreated vs. 0.9 virions/cell, treated, $p<0.001$; Figure 3Evs. 3F). Based on the observed disruption of virus attachment, MPXV entry was not examined. This different target of inhibition is consistent with the different pattern of EB susceptibility displayed by MPXV in the yield reduction assay compared to that demonstrated by CPXV and VACV. As inhibition of both CPXV and MPXV by EB occurs extracellularly, it is unlikely that the peptide's previously-described ability to inhibit NF- $\kappa \mathrm{B}$ signaling [1] is involved in its anti-orthopoxvirus activity.

EB has shown efficacy in an in vivo model of lethal influenza infection when added at the time of infection

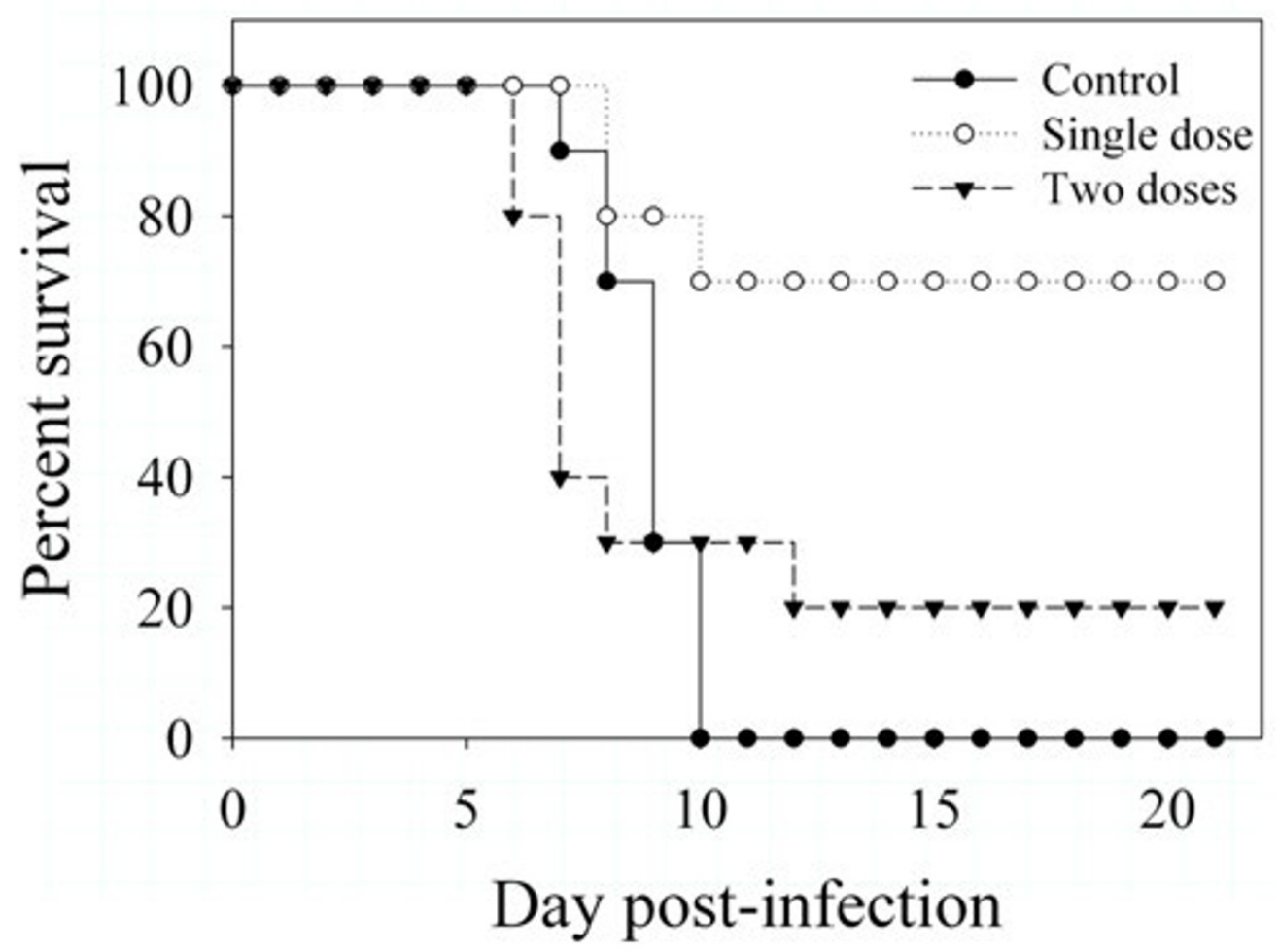

Figure 4 In vivo activity of EB. Ten female BALB/C mice were inoculated intranasally with $20 \mu \mathrm{L}$ containing $10^{5}$ PFU VACV (Control) or $10^{5}$ PFU VACV mixed with $10 \mathrm{mg} / \mathrm{kg}$ EB (Single dose) in PBS on day 0 . One additional group of animals received a second dose of EB intranasally on day 3 (Two doses). Animal survival was monitored for 21 days, and mice were euthanized when they met established endpoint criteria. 
or daily starting 6 hours post-infection [3] but has not been tested against any orthopoxviruses. As there is currently no well-characterized mouse model for MPXV infection available, EB was only tested against VACV (strain WR) and CPXV (strain Brighton) in vivo. To test EB for in vivo efficacy against VACV, EB $(10 \mathrm{mg} / \mathrm{kg})$ was administered intranasally concurrently with $10^{5}$ PFU of VACV (strain WR). Seventy percent of infected animals treated with a single dose of EB at the time of infection survived to study end, compared to no survivors in untreated animals (Figure 4). Two doses of EB (day 0, day 3) were less effective than a single dose, with only $20 \%$ of animals surviving. Animals receiving 2 doses met clinical endpoint criteria slightly earlier than control animals, which may suggest that further intranasal treatment exacerbated disease. EB showed no efficacy when administered prophylactically (1 day pre-infection) or therapeutically (1 day post-infection) to VACVinfected mice (data not shown). EB also demonstrated no efficacy when administered prophylactically, at the time of infection, or therapeutically to mice infected intranasally with CPXV (data not shown).

In summary, we were able to demonstrate in vivo efficacy of EB against VACV but not CPXV, despite both viruses having similar sensitivities to the peptide in vitro. The reasons for this difference are as yet unclear. EB was only effective against VACV when co-administered with the virus, suggesting that the peptide needed direct interaction with the virus to be effective. EB selfassociates in micelle-like structures at high concentrations and in high ionic buffers [12], a property which could influence bioavailability. It is possible that the in vivo anti-orthopoxvirus activity could therefore be improved by changing the vehicle used for delivery.

Most intriguing is the observation that EB inhibited attachment by MPXV but blocked entry by CPXV, as these processes are generally believed to be highly conserved between the orthopoxviruses. While EB has now been shown to have activity in vivo against VACV and influenza viruses [3], its greatest potential with orthopoxviruses may be as a novel in vitro tool to study the poorly-characterized early steps in infection. To date, over a dozen viral proteins are believed to be involved in orthopoxvirus attachment and entry [13-25]. The precise mechanisms of attachment and entry, however, have yet to be elucidated. Identification of the precise targets of the interaction between EB and VACV, CPXV, and MPXV could help identify key amino acids or structural features necessary for these processes and identify targets for novel inhibitors of infection.

\section{Acknowledgements}

The authors thank Grant McFadden (University of Florida) for the gift of the cowpox-GFP virus and Roselyn Eisenberg and Gary Cohen for the R236 anti- core antibody. The authors thank Russ Byrum, Isis Alexander and Bernardo Rosa for technical assistance. This work was supported in part by the NIAID Division of Intramural Research and by grants AI52049 and EYP30-016665 to Curtis R. Brandt. All animal work was performed under a NIAID-approved protocol and in compliance with NIAID's Institutional Animal Care and Use Committee.

\section{Author details}

${ }^{1}$ Emerging Viral Pathogens Section, National Institute of Allergy and Infectious Diseases, National Institutes of Health, Bethesda, MD 20892, USA. ${ }^{2}$ Departments of Ophthalmology \& Visual Sciences and Medical Microbiology \& Immunology, University of Wisconsin, Madison, WI 53706, USA. ${ }^{3}$ Integrated Research Facility, National Institute of Allergy and Infectious Diseases, National Institutes of Health, Fort Detrick, MD 21702, USA.

\section{Authors' contributions}

SEA carried out the in vitro and in vivo experiments, and SEA and JEB drafted the manuscript. SEA, CRB, PBJ and JEB participated in study design. All authors read and approved the final manuscript.

\section{Competing interests}

The authors declare that they have no competing interests.

Received: 2 November 2011 Accepted: 6 January 2012

Published: 6 January 2012

\section{References}

1. Lin $Y$-Z, Yao S, Veach RA, Torgerson TR, Hawiger J: Inhibition of nuclear translocation of transcription factor NF-KB by a synthetic peptide containing a cell membrane-permeable motif and nuclear localization sequence. J Biol Chem 1995, 270:14255-14258.

2. Bultmann H, Busse JS, Brandt CR: Modified FGF4 signal peptide inhibits entry of herpes simplex virus type 1. J Virol 2001, 75:2634-2645.

3. Jones JC, Turpin EA, Bultmann H, Brandt CR, Schultz-Cherry S: Inhibition of influenza virus infection by a novel antiviral peptide that targets attachment to cells. J Virol 2006, 80:11960-11967.

4. Jones JC, Settles EW, Brandt CR, Schultz-Cherry S: Identification of the minimal active sequence of an anti-influenza virus peptide. Antimicrob Agents Chemother 2011, 55:1810-1813.

5. Altmann SE, Jones JC, Schultz-Cherry S, Brandt CR: Inhibition of vaccinia virus entry by a broad spectrum antiviral peptide. Virology 2009, 388:248-259.

6. Akkarawongsa R, Cullinan AE, Zinkel A, Clarin J, Brandt CR: Corneal toxicity of cell-penetrating peptides that inhibit herpes simplex virus entry. $J$ Ocul Pharmacol Ther 2006, 22:279-289.

7. WHO: Declaration of global eradication of smallpox. Weekly Epidemiol Rec 1980, 55:148.

8. Essbauer S, Pfeffer M, Meyer H: Zoonotic poxviruses. Vet Microbiol 2010, 140:229-236.

9. Rimoin AW, Mulembakani PM, Johnston SC, Lloyd Smith JO, Kisalu NK, Kinkela TL, Blumberg S, Thomassen HA, Pike BL, Fair JN, et al: Major increase in human monkeypox incidence 30 years after smallpox vaccination campaigns cease in the democratic republic of Congo. Proc Natl Acad Sci USA 2010, 107:16262-16267.

10. Ježek Z, Fenner F: Human Monkeypox New York: Karger; 1988.

11. Law M, Smith GL: Studying the binding and entry of the intracellular and extracellular enveloped forms of vaccinia virus. Methods Mol Biol 2004, 269:187-204.

12. Bultmann H, Girdaukas G, Kwon GS, Brandt CR: The virucidal EB peptide protects host cells from herpes simplex virus type 1 infection in the presence of serum albumin and aggregates proteins in a detergent-like manner. Antimicrob Agents Chemother 2010, 54:4275-4289.

13. Chung CS, Hsiao JC, Chang YS, Chang W: A27L protein mediates vaccinia virus interaction with cell surface heparan sulfate. J Virol 1998, 72:1577-1585.

14. Hsiao JC, Chung CS, Chang W: Vaccinia virus envelope D8L protein binds to cell surface chondroitin sulfate and mediates the adsorption of intracellular mature virions to cells. J Virol 1999, 73:8750-8761.

15. Senkevich TG, Ward BM, Moss B: Vaccinia virus entry into cells is dependent on a virion surface protein encoded by the $\mathrm{A} 28 \mathrm{~L}$ gene. $J$ Virol 2004, 78:2357-2366. 
16. Senkevich TG, Moss $B$ : Vaccinia virus $H 2$ protein is an essential component of a complex involved in virus entry and cell-cell fusion. $J$ Virol 2005, 79:4744-4754.

17. Senkevich TG, Ojeda S, Townsley A, Nelson GE, Moss B: Poxvirus multiprotein entry-fusion complex. PNAS 2005, 102:18572-18577.

18. Townsley AC, Senkevich TG, Moss B: Vaccinia virus A21 virion membrane protein is required for cell entry and fusion. J Virol 2005, 79:9458-9469.

19. Townsley AC, Senkevich TG, Moss B: The product of the vaccinia virus $L 5 R$ gene is a fourth membrane protein encoded by all poxviruses that is required for cell entry and cell-cell fusion. J Virol 2005, 79:10988-10998.

20. Brown E, Senkevich TG, Moss B: Vaccinia virus F9 virion membrane protein is required for entry but not virus assembly, in contrast to the related L1 protein. J Virol 2006, 80:9455-9464.

21. Izmailyan RA, Huang CY, Mohammad S, Isaacs SN, Chang W: The envelope G3L protein is essential for entry of vaccinia virus into host cells. J Virol 2006, 80:8402-8410.

22. Ojeda S, Domi A, Moss B: Vaccinia virus G9 protein is an essential component of the poxvirus entry-fusion complex. J Virol 2006, 80:9822-9830.

23. Bisht $H$, Weisberg AS, Moss $B$ : Vaccinia virus $L 1$ protein is required for cell entry and membrane fusion. J Virol 2008, 82:8687-8694.

24. Nichols RJ, Stanitsa E, Unger B, Traktman P: The Vaccinia virus gene I2L encodes a membrane protein with an essential role in virion entry. $J$ Virol 2008, 82:10247-10261.

25. Satheshkumar PS, Moss B: Characterization of a newly identified 35amino-acid component of the vaccinia virus entry/fusion complex conserved in all chordopoxviruses. J Virol 2009, 83:12822-12832.

doi:10.1186/1743-422X-9-6

Cite this article as: Altmann et al: Antiviral activity of the EB peptide against zoonotic poxviruses. Virology Journal 2012 9:6.

\section{Submit your next manuscript to BioMed Central and take full advantage of:}

- Convenient online submission

- Thorough peer review

- No space constraints or color figure charges

- Immediate publication on acceptance

- Inclusion in PubMed, CAS, Scopus and Google Scholar

- Research which is freely available for redistribution

Submit your manuscript at www.biomedcentral.com/submit 